\title{
Occurrence of SHV, TEM and CTX-M $\beta$-Lactamase Genes Among Enteropathogenic Escherichia coli Strains Isolated From Children With Diarrhea
}

\author{
Mojtaba Memariani ${ }^{1}$; Shahin Najar-Peerayeh ${ }^{1,}$; Taghi Zahraei Salehi ${ }^{2}$; Seyyed Khalil \\ Shokouhi Mostafavi ${ }^{3}$ \\ ${ }^{1}$ Department of Bacteriology, Faculty of Medical Sciences, Tarbiat Modares University, Tehran, IR Iran \\ ${ }^{2}$ Department of Microbiology, Faculty of Veterinary Medicine, University of Tehran, Tehran, IR Iran \\ ${ }^{3}$ Department of Microbiology, Tonekabon Branch, Islamic Azad University, Tonekabon, IR Iran \\ ${ }^{*}$ Corresponding author: Shahin Najar Peerayeh, Department of Bacteriology, Faculty of Medical Sciences, Tarbiat Modares University, Tehran, IR Iran. Tel: +98-2182883870, Fax: \\ +98-2182884555, E-mail: najarp_s@modares.ac.ir
}

Received: October 25, 2013; Revised: December 20, 2013; Accepted: December 28, 2013

\begin{abstract}
Background: Antibiotic resistance is widespread among diarrheagenic Escherichia coli in developing countries, where the overuse of antibiotics is common. Information regarding $\beta$-lactamases, especially Extended-Spectrum $\beta$-Lactamases (ESBLs) in diarrheagenic pathogens should be considered in clinical management when an optimal treatment is needed.

Objectives: The main objective of this study was to investigate the prevalence of bla ${ }_{C T X-M}, b_{S H V}$ and $b_{T E M}{ }^{\beta-l a c t a m a s e ~ g e n e s ~ a m o n g ~}$ enteropathogenic E. coli (EPEC) isolates in Tehran, Iran.

Materials and Methods: Stool specimens were collected from children with diarrhea during a 17-month period from 2011 to 2013 . Routine biochemical tests were performed for identification of $E$. coli isolates. The isolates were further examined by PCR for the presence of eae, stx1, stx2 and bfp genes. EPEC isolates have been screened for different $\beta$-lactamase genes. Genotyping EPEC isolates harboring bla ${ }_{C T X-M 15}$ gene was performed through Multi-Locus VNTR Analysis (MLVA).

Results: Of $42 \mathrm{EPEC}$, eight isolates carried the bla ${ }_{C T X-M 1}$. None of the isolates carried bla ${ }_{C T X-M 2}$ and bla ${ }_{C T X-M 9}$. The bla ${ }_{C T X-M 15}$ variant was identified in all of $b l a_{C T X-M 1}$-positive isolates. Furthermore, $b l a_{S H V}$ and $b l a a_{T E M}$ genes were detected in $40.5 \%(\mathrm{n}=17)$ and $19 \%(\mathrm{n}=8)$ of all EPEC isolates, respectively. No significant association was observed between the existence of $b f p$ gene and presence of those $\beta$-lactamase genes $(\mathrm{P}>0.05)$. MLVA analysis revealed high genetic diversity among bla ${ }_{C T X-M 15}$-positive isolates.

Conclusions: Our study emphasized the increasing role of ESBL genes, especially bla ${ }_{C T X-M 15}$ in EPEC isolates.
\end{abstract}

Keywords: Enteropathogenic Escherichia coli; Strains; Diarrhea

\section{Background}

Enteropathogenic Escherichia coli (EPEC) is a leading cause of infantile diarrhea in developing countries. These pathogens are characterized by their ability to cause attaching and effacing lesions in intestinal mucosa. The lesions are directed by a pathogenicity island (PAI) known as Locus of Enterocyte Effacement (LEE), which encodes a type III secretion apparatus, intimin and effector proteins. Typical EPEC (tEPEC) strains have fimbrial adhesion called bundle-forming pili (BFP) and maybe more pathogenic than atypical strains which do not possess it (1). In developing countries, in most cases, EPEC isolates recovered from humans with diarrhea are tEPEC; however, in industrial countries, most strains do not possess BFP and are identified as atypical EPEC (aEPEC) (2).

The spread of extended-spectrum $\beta$-lactamases (ESBLs) is an emerging global public health problem. Most ESBL genes are mutant derivatives of the classical bla $a_{S H V}$ and bla $_{\text {TEM }} \beta$-lactamases, but a rapid increase in the preva- lence of bla $C T X-M$ has been reported among Enterobacteriaceae over the last decade. These genes are capable of conferring resistance to third-generation cephalosporins (e.g. ceftazidime and cefotaxime) and aztreonam, but not cephamycins (e.g. cefoxitin) and carbapenems (3). In contrast to ESBLs, AmpC $\beta$-lactamases are poorly inhibited by clavulanic acid and are active against cephamycins (4). Antibiotic resistance is on the rise among diarrheagenic E. coli in developing countries, where overuse and misuse of antibiotics is common $(5,6)$. Furthermore, emergence of ESBL genes within commensal E. coli isolates in children is a matter of concern and has long been known that these bacteria are potential reservoirs for those genes in both community and hospital settings $(7,8)$. Therefore, information regarding ESBLs as well as other classes of $\beta$-lactamases in diarrheagenic pathogens should be considered in clinical management when an optimal treatment is needed (6). EPEC still plays an important role as

Copyright (C) 2015, Ahvaz Jundishapur University of Medical Sciences. This is an open-access article distributed under the terms of the Creative Commons Attribution-NonCommercial 4.0 International License (http://creativecommons.org/licenses/by-nc/4.0/) which permits copy and redistribute the material just in noncommercial usages, provided the original work is properly cited. 
a causative agent of infantile diarrhea in our country ( 9 , 10). Although there were epidemiological surveys regarding prevalence of EPEC in Iran, none of these studies investigated the occurrence of $\beta$-lactamase genes in those isolates.

\section{Objectives}

Considering the paucity of epidemiological data on the issue, this study was designed to estimate the prevalence of bla ${ }_{C T X-M}$, bla $a_{S H V}$ and bla ${ }_{T E M}$ genes among EPEC strains obtained from children with diarrhea. The second objective was to determine the genetic diversity among ESBL producing strains.

\section{Materials and Methods}

\subsection{Sampling and Detection of EPEC Strains}

Stool specimens were obtained from children with diarrhea ( $\leq 10$ years old) during 17 months (September 2011 to January 2013). The sample size was calculated using the following formula: $\mathrm{N}=\mathrm{Z}^{2} \mathrm{pq} / \mathrm{d} 2$. Thus, a sample size (n) of 350 patients was sufficient, assuming that the prevalence (p) of EPEC in children was $9 \%(9,10)$. The expected margin of errors (d) was 0.04 and the confidence interval (CI) was 95\%. The patients were admitted to one of three pediatric hospitals in Tehran. They had evidence of more than three episodes of watery, loose or bloody stools per day. In Brief, all stool suspensions (one stool per patient) were inoculated directly onto MacConkey agar (Merck, Germany) plates and incubated at $37^{\circ} \mathrm{C}$ for 24 hours. For detection of E. coli strains, up to five lactose-positive colonies per plate were selected and subjected to routine biochemical tests (Gram staining, oxidase test, indole production, $\mathrm{H} 2 \mathrm{~S}$ production, carbohydrate utilization on TSI agar, MRVP reaction, urease production, etc.).

For DNA extraction, several colonies of the pure isolate were suspended in $500 \mu \mathrm{L}$ of distilled water and heated at $100^{\circ} \mathrm{C}$ for 10 minutes. Then, it was centrifuged at $8000 \mathrm{~g}$ for 8 minutes. The supernatant was used as PCR template. To confirm EPEC strains, each E. coli isolate was examined by PCR with specific eae primers (Cinagen Co., Iran) using Eppendorf thermal cycler (Eppendorf AG, Germany) (11). Table 1 summarizes the primer sequences, annealing temperatures and the expected size of the PCR products. PCR was performed in a reaction mixture with total volume of $25 \mu \mathrm{L}$, containing $20 \mu \mathrm{L}$ sterile water, $50 \mathrm{ng}$ of template DNA, $2.5 \mu \mathrm{L}$ 10X Taq polymerase buffer, $0.3 \mu \mathrm{L}$ dNTPs (10 mmol/L), $1 \mathrm{U}$ Taq DNA polymerase and $0.4 \mathrm{~mol} / \mathrm{L}$ of each primer. The PCR program consisted of an initial denaturation step at $94^{\circ} \mathrm{C}$ for 4 minutes, followed by $32 \mathrm{cy}$ cles of denaturation at $93^{\circ} \mathrm{C}$ for 30 seconds, annealing at $55^{\circ} \mathrm{C}$ for 30 seconds and extension at $72^{\circ} \mathrm{C}$ for 40 seconds. After the last cycle, a final extension at $72^{\circ} \mathrm{C}$ for 4 minutes was performed. Three microliters of PCR product were analyzed by gel electrophoresis with $1 \%$ agarose (Bio-Rad,
United States). Gels were stained with ethidium bromide and visualized by UV transillumination. The presence of stx1, stx2 and bfp genes in eae-positive strains was further evaluated by PCR $(12,13)$. Reactions were performed in the same conditions as described above, except for annealing temperatures (Table 1). E. coli strains ATCC 2348/9 (eae and $b f p)$ and EDL933 (stx1 and stx2) were used as positive controls (9). The isolates were preserved in tryptic soy broth with $20 \%$ glycerol and stored at $-70^{\circ} \mathrm{C}$.

\subsection{Serogrouping}

Serogrouping using polyvalent antisera (Mast, United Kingdom) was performed for confirmed EPEC strains according to manufacturer's instructions. The polyvalent antisera consist of three separated pools, able to react with the following serogroups: poly group 2 (O26, O55, O111, O119 and O126), poly group 3 (O86, O114, O125, O127 and $\mathrm{O128}$ ) and poly group 4 (O44, O112, 0124 and 0142 ). Strains agglutinated with polyvalent antisera were retested by monovalent $\mathrm{O}$ antisera.

\subsection{Antibiotic Susceptibility Testing}

The antibiotic susceptibility testing was performed on Mueller-Hinton agar by disk diffusion method. The following antibiotics (Mast, United Kingdom) were tested as recommended by CLSI 2010 guidelines: Ampicillin (10 $\mu \mathrm{g})$, augmentin $(30 \mu \mathrm{g})$, ceftazidime $(30 \mu \mathrm{g})$, cefotaxime $(30 \mu \mathrm{g})$, trimethoprim-sulfamethoxazole $(25 \mu \mathrm{g})$, ciprofloxacin $(5 \mu \mathrm{g})$, tetracycline $(30 \mu \mathrm{g})$, chloramphenicol $(30 \mu \mathrm{g})$, aztreonam $(30 \mu \mathrm{g})$, imipenem $(10 \mu \mathrm{g})$ and cefoxitin $(30 \mu \mathrm{g})$. E. coli ATCC 25922 was used as the quality control (14).

\subsection{Phenotypic Detection of ESBL Production}

The EPEC isolates with resistance to any of tested thirdgeneration cephalosporins (i.e. ceftazidime and cefotaxime) were further analyzed using both ceftazidime (30 $\mu \mathrm{g})$ /ceftazidime $(30 \mu \mathrm{g})$ combined with clavulanic acid $(10 \mu \mathrm{g})$ and cefotaxime $(30 \mu \mathrm{g}) /$ cefotaxime $(30 \mu \mathrm{g}) \mathrm{com}$ bined with clavulanic acid $(10 \mu \mathrm{g})$. CLSI suggests making disks by adding $10 \mu \mathrm{L}$ of a $1000 \mu \mathrm{g} / \mathrm{mL}$ stock solution of clavulanic acid to cefotaxime and ceftazidime disks. ESBL production was confirmed if the zones produced by the disks with clavulanate were $\geq 5 \mathrm{~mm}$ larger than those without the inhibitor (15).

\subsection{Molecular Detection of $\beta$-Lactamase Genes}

PCR was performed for detection of bla ${ }_{C T X-M 1}$, bla $C$ TX-M2 and bla $C$ TX-M9 genes (16). The isolates positive for bla $C T X$ $M_{1}$ group were further analyzed by PCR with bla $\mathrm{CTX}$-M15 specific primers (17). All isolates were also screened for bla $_{S H V}$ and bla TEM $_{\text {genes (Table } 1)}(18,19)$. PCR conditions were the same as described above, except for annealing temperatures (Table 1). Clinical strains carrying those $\beta$-lactamase genes were used as positive controls. 
Memariani M et al.

Table 1. Primers Used in This Study for Detection of EPEC Strains and $\beta$-Lactamase Genes

\begin{tabular}{|c|c|c|c|}
\hline Gene & Primer Sequence (5' to 3') & Size of Amplicon, bp & Annealing Temperature, ${ }^{\circ} \mathrm{C}$ \\
\hline \multirow[t]{3}{*}{ eae } & & 229 & 55 \\
\hline & F-CTGAACCAGATCGTAACGGC & & \\
\hline & R-TGATAAGCTGCAGTCGAATCC & & \\
\hline \multirow[t]{3}{*}{ bfp } & & 326 & 58 \\
\hline & F-AATGGTGCTTGCGCTTGCTGC & & \\
\hline & R-GCCGCTTTATCCAACCTGGTA & & \\
\hline \multirow[t]{3}{*}{ stx1 } & & 302 & 55 \\
\hline & F-CGCTGAATGTCATTCGCTCTGC & & \\
\hline & R-CGTGGTATAGCTACTGTCACC & & \\
\hline \multirow[t]{3}{*}{ stx2 } & & 516 & 56 \\
\hline & F-CCTCGGTATCCTATTCCCGG & & \\
\hline & R-CTGCTGTGACAGTGACAAAACGC & & \\
\hline \multirow[t]{3}{*}{ blaCTX-M1 } & & 863 & 54 \\
\hline & F-GGTTAAAAAATCACTGCGTC & & \\
\hline & R-TTGGTGACGATTTTAGCCGC & & \\
\hline \multirow[t]{3}{*}{ blaCTX-M2 } & & 865 & 54 \\
\hline & F-ATGATGACTCAGAGCATTCG & & \\
\hline & R-TGGGTTACGATTTTCGCCGC & & \\
\hline \multirow[t]{3}{*}{ blaCTX-M9 } & & 869 & 54 \\
\hline & F-ATGGTGACAAAGAGAGTGCA & & \\
\hline & R-CCCTTCGGCGATGATTCTC & & \\
\hline \multirow[t]{3}{*}{ blaCTX-M15 } & & 995 & 55 \\
\hline & F-CACACGTGGAATTTAGGGACT & & \\
\hline & R-GCCGTCTAAGGCGATAAACA & & \\
\hline \multirow[t]{3}{*}{ SHV } & & 230 & 56 \\
\hline & F-AAGATCCACTATCGCCAGCAG & & \\
\hline & R-ATTCAGTTCCGTTTCCCAGCGG & & \\
\hline \multirow[t]{3}{*}{ blaTEM } & & 856 & 53 \\
\hline & F-ATGAGTATTCAACATTTCCGC & & \\
\hline & R-CAATGCTTAATCAGTGAGG & & \\
\hline
\end{tabular}

\subsection{Determination of Minimum Inhibitory Con- centrations (MICs)}

All isolates harboring bla $C T X-M$ were subjected to MIC testing for ceftazidime and cefotaxime by agar dilution according to CLSI 2010 guidelines. E. coli ATCC 25922 was used as control strain (14).

\subsection{Genotyping of CTX-M15-Producing EPEC Strains by MLVA Analysis}

Multi Locus VNTR Analysis (MLVA) was performed for isolates with positive results for bla $C T X-M 15$ gene as described by Gorge et al. (20). The PCR primers and repeat sizes for each locus are listed in Table 2. PCR was performed separately for each locus in a reaction mixture with total volume of $25 \mu \mathrm{L}$, containing $20 \mu \mathrm{L}$ sterile water, $50 \mathrm{ng}$ of template DNA, $2.5 \mu \mathrm{L}$ 10X Taq polymerase buffer, $0.3 \mu \mathrm{L}$ dNTPs
(10 mmol/L), $1 \mathrm{U}$ Taq DNA polymerase and $0.4 \mathrm{~mol} / \mathrm{L}$ of each primer. The PCR program consisted of an initial denaturation step at $94^{\circ} \mathrm{C}$ for 4 minutes, followed by 32 cycles of denaturation at $93^{\circ} \mathrm{C}$ for 30 seconds, annealing at $55^{\circ} \mathrm{C}$ for 30 seconds and extension at $72^{\circ} \mathrm{C}$ for 60 seconds. After the last cycle, a final extension at $72^{\circ} \mathrm{C}$ for 4 minutes was performed. The size of each locus (PCR amplicon) was easily determined by gel electrophoresis with $2 \%$ agarose. The repeat copy numbers deduced for each isolate using the formula: Number of repeats (bp) $=$ [size of each locus (bp)flanking regions (bp)]/repeat size (bp). The null allele was given when the locus failed to amplify in PCR assay. After entering data into Microsoft Excel 2010 (Redmond, WA, USA), the distance matrix was calculated with the categorical coefficient using the web-based MIRU-VNTRplus (www. mlvaplus.net) (21). This distance matrix was imported into MEGA v5 to generate an unweighted-pair group method using average linkages (UPGMA) dendrogram (22). 
Memariani M et al.

\begin{tabular}{|c|c|c|c|}
\hline Loci & Primer Sequence (5' to 3') & Repeat Sizes at Each Locus, bp & Annealing Temperature, ${ }^{\circ} \mathrm{C}$ \\
\hline \multirow[t]{3}{*}{ mso6 } & & 39 & 55 \\
\hline & F-AAACGGGAGAGCCGGTTATT & & \\
\hline & R-TGTTGGTACAACGGCTCCTG & & \\
\hline \multirow[t]{3}{*}{ ms07 } & & 39 & 55 \\
\hline & F-GTCAGTTCGCCCAGACACAG & & \\
\hline & R-CGGTGTCAGCAAATCCAGAG & & \\
\hline \multirow[t]{3}{*}{ mso9 } & & 179 & 55 \\
\hline & F-GTGCCATCGGGCAAAATTAG & & \\
\hline & R-CCGATAAGGGAGCAGGCTAGT & & \\
\hline \multirow[t]{3}{*}{ ms11 } & & 96 & 55 \\
\hline & F-GAAACAGGCCCAGGCTACAC & & \\
\hline & R-CTGGCGCTGGTTATGGGTAT & & \\
\hline \multirow[t]{3}{*}{ ms21 } & & 141 & 55 \\
\hline & F-GCTGATGGCGAAGGAGAAGA & & \\
\hline & R-GGGAGTATGCGGTCAAAAGC & & \\
\hline \multirow[t]{3}{*}{ ms23 } & & 375 & 55 \\
\hline & F-GCTCCGCTGATTGACTCCTT & & \\
\hline & R-CGGTTGCTCGACCACTAACA & & \\
\hline \multirow[t]{3}{*}{ ms32 } & & 101 & 55 \\
\hline & F-GAGATTGCCGAAGTGTTGC & & \\
\hline & R-AACTGGCGGCGTTTATCAAG & & \\
\hline
\end{tabular}

\subsection{Statistical Analysis}

Fisher's exact test (SPSS version 17.0) was used to examine the significance of association between different $\beta$-lactamase genes and the presence of $b f p$ gene. The test is recommended for the analysis of contingency tables when sample sizes are small. The level of statistical significance was set at $\mathrm{P}<0.05$.

\section{Results}

Of 349 stool specimens (one stool per patient), $398 \mathrm{E}$. coli isolates were recovered. Of these isolates, 42 were EPEC. Therefore, EPEC was recovered from $12 \%$ of patients. These isolates comprised 16 tEPEC and 26 aEPEC (Figure 1). The mean age of patients was $2.7 \pm 2.3 \mathrm{SD} ; 24$ (57.1\%) were females and 18 (42.9\%) males, with a femaleto-male ratio of $1.3: 1$.

\subsection{Serogrouping}

The most common serogroups among EPEC isolates were the members of $\mathrm{O} 127(\mathrm{n}=5,12 \%)$ and $\mathrm{O} 142(\mathrm{n}=5,12 \%)$, followed by O86 $(\mathrm{n}=4,9.5 \%), \mathrm{O} 28(\mathrm{n}=2,4.8 \%), \mathrm{O} 111(\mathrm{n}=1,2.4 \%)$ and $044(n=1,2.4 \%)$. However, most isolates $(n=24,57.1 \%)$ were nontypeable (ONT) with polyvalent antisera used.

\subsection{Antibiotic Susceptibilities of EPEC Strains}

All isolates ( $n=42,100 \%$ ) were susceptible to imipenem and cefoxitin. High resistance rates were observed against ampicillin ( $n=26,61.9 \%)$, followed by co-trimoxa- zole $(\mathrm{n}=23,54.8 \%)$, augmentin $(\mathrm{n}=18,42.9 \%)$, tetracycline ( $n=16,38.1 \%)$, cefotaxime $(n=9,21.4 \%)$, ceftazidime $(n=$ $8,19 \%)$, aztreonam $(n=8,19 \%)$ and ciprofloxacin $(n=7$, $16.7 \%$ ). By contrast, only one isolate was resistant to chloramphenicol.

\subsection{Phenotypic ESBL Detection}

Phenotypic confirmatory test using cefotaxime in combination with clavulanic acid as an inhibitor revealed that of 42 EPEC, nine (21.4\%) isolates were ESBL producers. However, only eight isolates had positive results when the test was performed with ceftazidime. An increase of 5 $\mathrm{mm}$ in the zone of inhibition for either ceftazidime or cefotaxime tested in combination with clavulanic acid versus its zone when tested alone indicated that the isolate was an ESBL producer.

\subsection{Detection of $\beta$-lactamase Genes}

PCR was performed for all EPEC strains. Of nine ESBL producers, eight carried the bla $C T X-M 1$. None of the isolates carried bla ${ }_{C T X-M 2}$ and bla CTX-M9. Subsequent PCR revealed that all of the bla $C$ CX-M1-positive isolates harbored bla $C T X-M 15$ subtype. Of these eight isolates, three were tEPEC (BFP-positive), while the remaining five isolates belonged to aEPEC (BFP-negative). Statistical analysis showed that the presence of bla CTX-M15 was not associated with existence of $b f p$ gene ( $P>0.05$ by Fisher's exact test). Of eight bla ${ }_{C T X}$-M15-positive isolates, only one isolate was typeable with polyvalent antisera used (Table 
Memariani $M$ et al.

3). On the other hand, bla $a_{S H V}$ and bla $a_{\text {TEM }}$ genes were detected in $40.5 \%(n=17)$ and $19 \%(n=8)$ of all EPEC isolates, respectively (Figure 2). Similarly, a significant association was not observed between existence of $b f p$ gene and presence of bla ${ }_{S H V}$ or bla $a_{\text {TEM }}(\mathrm{P}>0.05$ by Fisher's exact test). Furthermore, coexistence of bla $C T X-M 15$ and other $\beta$-lactamase genes in a single isolate was common. The bla $_{\text {CTX-M15 }}$ was found to coexist with bla ${ }_{S H V}$ in four isolates. One isolate harbored both bla CTX-M15 and bla TEM

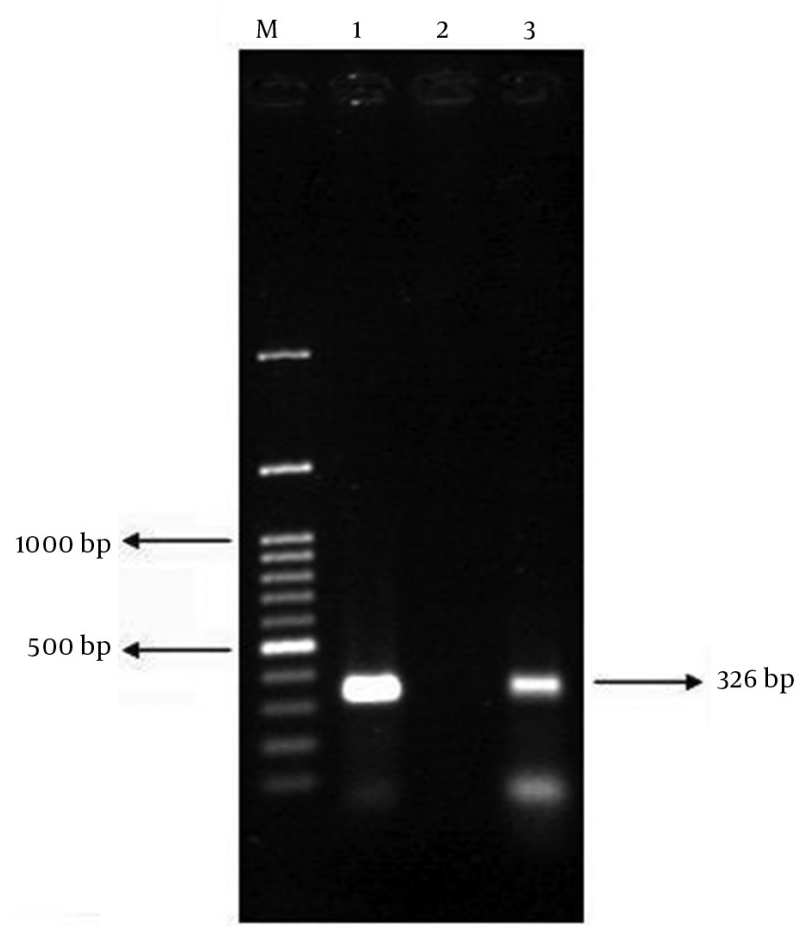

Figure 1. PCR Results of $b f p$ Gene on Agarose Gel; Positive Control (Lane 1), Negative Control (Lane 2), and a Positive Clinical Isolate (Lane 3) genes together, while the other one simultaneously carried bla ${ }_{C T X-M 15}$, bla $_{T E M}$ and bla ${ }_{S H V}$ genes.

\subsection{MIC Results}

Of eight CTX-M15-positive isolates, seven isolates had MICs of $128(\mu \mathrm{g} / \mathrm{mL})$ against ceftazidime. However, all CTX-M15-positive isolates typically exhibited higher $\operatorname{MICs}(256 \mu \mathrm{g} / \mathrm{mL})$ against cefotaxime (Table 3).

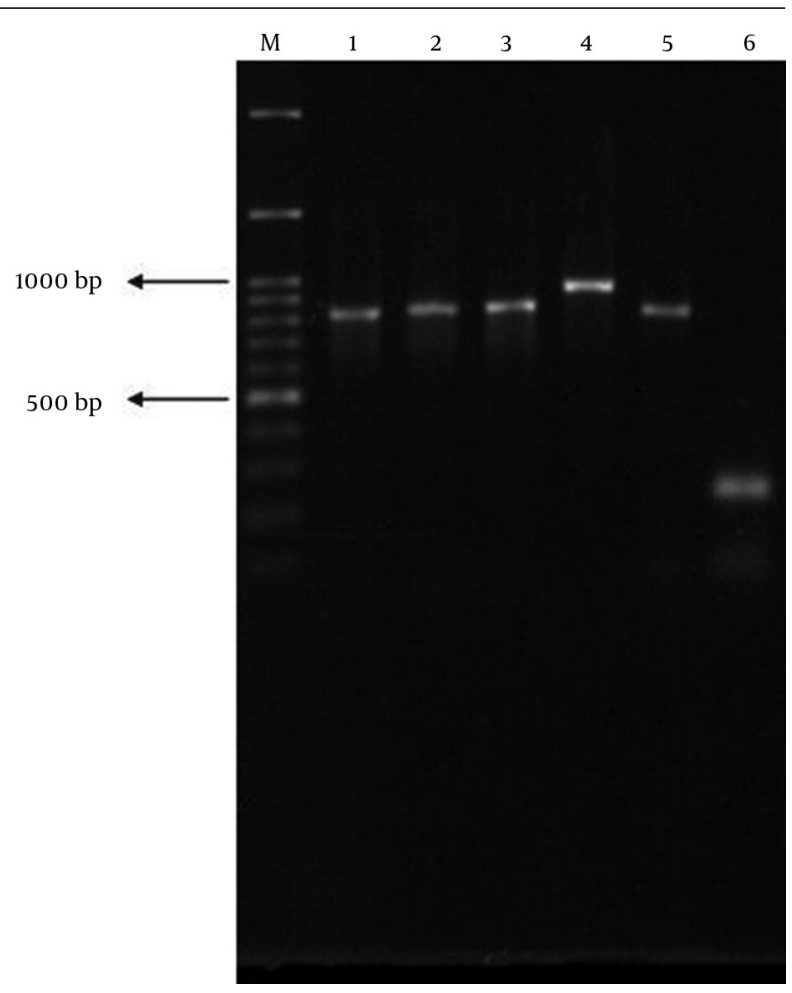

Figure 2. PCR Products of Positive Controls for Each $\beta$-Lactamase Gene; bla $_{\text {CTX-M1 }}$ (Lane 1), bla ${ }_{C T X-M 2}$ (Lane 2), bla ${ }_{C T X-M 9}$ (Lane 3), bla ${ }_{C T X-M 15}$ (Lane 4), bla ${ }_{T E M}$ (Lane 5), and bla ${ }_{S H V}$ (Lane 6)

\begin{tabular}{|c|c|c|c|c|c|c|c|c|c|c|}
\hline \multirow[t]{2}{*}{ Strains } & \multirow[t]{2}{*}{$b f p$} & \multirow[t]{2}{*}{ Serogroups } & \multirow[t]{2}{*}{ Patient sex } & \multirow[t]{2}{*}{ Patient age, $y$} & \multicolumn{3}{|c|}{$\beta$-lactamase Profile } & \multicolumn{2}{|c|}{ MICs, $\mu \mathrm{g} / \mathrm{ml}$} & \multirow[t]{2}{*}{ Resistance Profile } \\
\hline & & & & & CTX-M15 & SHV & TEM & CTX & CAZ & \\
\hline TMU49 & - & ONT & $\mathrm{F}$ & 1 & + & - & - & 256 & 128 & AmpAugAtmTsCip \\
\hline TMU106 & - & O127 & $\mathrm{F}$ & 1 & + & - & - & 256 & 128 & AmpAtmCip \\
\hline TMU157 & + & ONT & $\mathrm{F}$ & 1.5 & + & - & + & 256 & 128 & AmpAugAtmCip \\
\hline TMU164 & + & ONT & M & $<1$ & + & + & - & 256 & 64 & AmpAugAtm \\
\hline TMU251 & - & ONT & $\mathrm{F}$ & 1 & + & + & + & 256 & 128 & AmpAugCip \\
\hline TMU329 & - & ONT & $\mathrm{F}$ & 4 & + & + & - & 256 & 128 & AmpAugAtmTsTe \\
\hline TMU369 & - & ONT & M & 6 & + & + & - & 256 & 128 & AmpAtmTsTeCip \\
\hline TMU391 & + & ONT & $\mathrm{F}$ & 2 & + & + & - & 256 & 128 & AmpAtmTsTeCip \\
\hline
\end{tabular}

\footnotetext{
a Abbreviations: Amp, ampicillin; Atm, aztreonam; Aug, augmentin; CAZ, ceftazidime; Cip, ciprofloxacin; CTX, cefotaxime; F, female; M, male; ONT, O
} not typeable; Te, tetracycline; Ts, co-trimoxazole. 


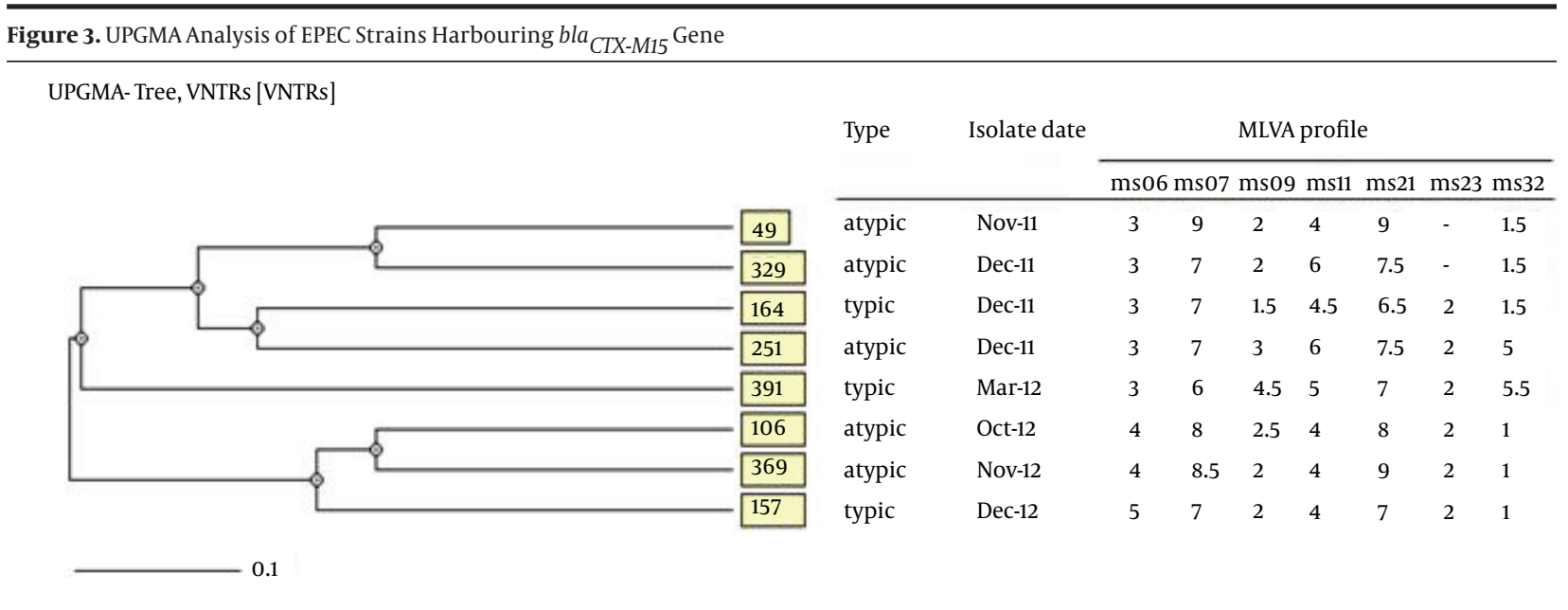

Additional information is shown on the right side.

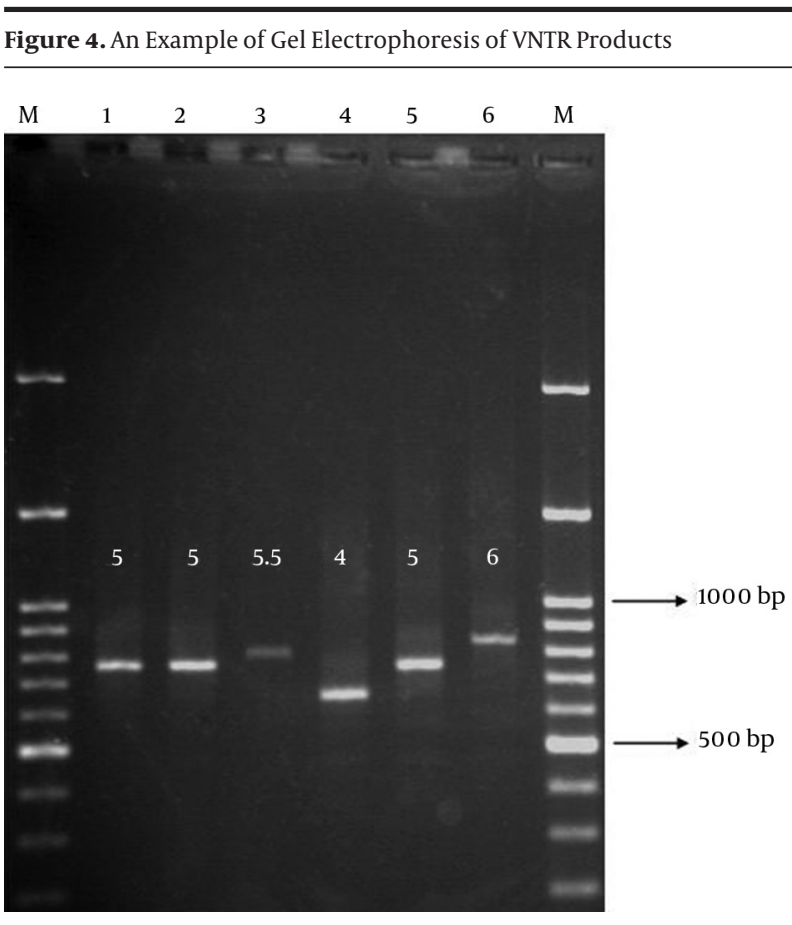

The PCR products of different isolates using "ms11" primers have been loaded on the agarose gel.

\subsection{MLVA Assay}

UPGMA cluster analysis revealed high genetic diversity among CTX-M15-producing isolates, which indicated lack of any significant genetic relatedness. MLVA distinguished eight unique genotypes, with the similarities ranged from $60 \%$ to $80 \%$ for the most and the least similar isolates, respectively (Figure 3). MLVA assay set-up for ms11 locus is shown in Figure 4. The image illustrates how the repeat copy numbers can be directly deduced by manual reading. The numbers above amplicons provide the repeat copy numbers for each strain.

\section{Discussion}

Over the last decade, bla ${ }_{C T X}{ }^{-M}$ has become increasingly common worldwide, to the point that their prevalence easily surpassing those of bla ${ }_{S H V}$ and bla ${ }_{T E M}$ ESBL genes. Based on CTX-M amino acid sequences, these enzymes have been classified into five major groups, groups 1,2 , 8,9 and 25/26. The incidence of these bla $C T X-M$ genotypes varies geographically. The most widely disseminated genotype, the bla ${ }_{C T X}-M 15$ has spread to all continents. It was first described in E. coli isolated from India during 2001. The bla CTX-M15 is sometimes associated with other genes, such as bla SHV $_{\text {and }}$ bla $a_{T E M}$ as well as genes encoding for resistance to other antibiotics, such as the qnr genes conferring resistance to fluoroquinolones, and aac (6')-Ib-cr, conferring resistance to aminoglycosides and fluoroquinolones (23).

In our country, previous studies revealed that the ${ }^{b l a}{ }_{C T X-M 1}$ was the dominant ESBL gene among clinical isolates of Klebsiella pneumoniae (24), Salmonella enterica (25) and Shigella spp.(26). Likewise, data on emergence of CTX-M15-producing Enterobacteriaceae from neighboring countries such as Kuwait (27), Saudi Arabia (28) and Turkey (29) is in accordance with our results. However, there are few reports regarding the incidence of bla $C T X$ M15 among diarrheagenic E. coli. In a study conducted by Albert et al. (30), the bla $C T X-M 28^{\text {was }}$ the most common bla $_{C T X-M}$ variant in enteroaggregative E. coli (EAEC) and EPEC in Kuwait. Both bla CTX-M28 and bla CTX-M15 genes are members of bla $a_{C T X-M 1}$ group. In UAE, the bla $\mathrm{CTX-M15}$ was the sole variant in EAEC (31). By contrast, EPEC strains carrying bla $a_{P E R-2}$ and bla TEM-116 ESBL genes have been recovered from children with diarrhea in South America (32). According to the study of Amaya et al. (33), EAEC was significantly more resistant than EPEC to various antibiotics in Nicaragua. They also showed that CTX-M15 enzyme was the main type of ESBL among EAEC and nondiarrheagenic E. coli isolates obtained from children with or without diarrhea (33). 
Some of ESBLs evolved from older, broad-spectrum $\beta$-lactamases (e.g. bla $a_{S H V-1}$ and $b l a_{T E M-1}$ ). The non-ESBL SHV-1 $\beta$-lactamase has been commonly encountered in $E$. coli and K. pneumoniae. Additionally, the gene is usually plasmid mediated in E. coli, but chromosomally encoded in most K. pneumoniae isolates (34). In this research, almost a half of the isolates harbored bla ${ }_{S H V}$ gene. Interestingly, the gene was coexisted with bla CTX-M15 in five isolates. However, most isolates expressing SHV enzyme were non-ESBL producers. Similarly, only two isolates harbored both bla $C T X-M 15$ and bla $a_{\text {TEM }}$ genes. The remaining TEM-positive isolates were non-ESBL producers. This finding is not surprising because TEM- 1 is the most frequently encountered $\beta$-lactamase among ampicillin resistant $E$. coli. Although these classical $\beta$-lactamases are not considered ESBLs, their clinical importance relies on their potential to undergo mutations to increase their activity against extended-spectrum $\beta$-lactams (e.g. third generation cephalosporins) (23).

In this study, all isolates were susceptible to cefoxitin, indicating that AmpC $\beta$-lactamases did not exist among them. Cefoxitin hydrolysis as a screening marker distinguishes AmpC from other $\beta$-lactamases. These enzymes represent a clinical threat since they are not affected by $\beta$-lactamases inhibitors (e.g. clavulanic acid). Furthermore, co-existence of AmpC $\beta$-lactamases and ESBLs in the same isolate can result in false-negative phenotypic confirmatory test, because clavulanic acid induces high level expression of AmpC $\beta$-lactamases (35). As for imipenem, none of the isolates were resistant to it, indicating that carbapenemases, especially those originated from molecular class A (e.g. KPC) were absent among our EPEC isolates (36). The most predominant O-serogroups were O127, O142, O86 and O128 in our study. Interestingly, most of CTX-M15-positive isolates were not typeable with diagnostic antisera. In a study conducted by Alikhani et al. (9) serogroups O127, O142, O111, O55 and O26 were the major groups, which were somewhat different from those of our work. On the other hand, Blanco et al. (37) showed that O55, O111 and O119 were the most common serogroups in Uruguay, whereas another study from Germany reported that $\mathrm{O} 26, \mathrm{O} 55, \mathrm{O} 86$ and 0128 were the most prevalent serogroups (38). Serogroups can also vary over time, by region, or even by same regions inside a country. In our research, most isolates were not typeable with the panel of diagnostic antisera. Indeed, the diversity of serogroups among EPEC strains discouraged the use of serotyping methods for their diagnosis (37-39). MLVA is a promising genotyping method, which is easy to perform, cheap and highly reproducible alternative to Pulse Field Gel Electrophoresis (PFGE) and Multi Locus Sequence Typing (MLST). MLVA has been used successfully to genotype ESBL-producing E. coli strains in Denmark (40). It was also applied for genotyping E. coli strains carrying different groups of CTX-M family in some European countries (41). The most obvious finding from this survey was that there was a high degree of heterogeneity among ESBL producing strains. The presence of these strains was not due to emergence of one specific clone, but seemed to be due to the spread of mobile genetic elements (e.g. plasmids and transposons) harboring bla CTX-M15 as well as other $\beta$-lactamase resistance genes. In conclusion, this study emphasized the alarming role of $\beta$-lactamases, especially ESBLs in antibiotic resistance in diarrheagenic $E$. coli strains. It gave us an insight into the current prevalence and genetic backgrounds of these strains.

\section{Acknowledgements}

The authors would like to thank Dr. Mohammad Mehdi Aslani for providing positive controls.

\section{Funding/Support}

This study was supported by grants from Faculty of Medical Sciences, Tarbiat Modares University, Tehran, IR Iran.

\section{References}

1. Clarke SC, Haigh RD, Freestone PP, Williams PH. Enteropathogenic Escherichia coli infection: history and clinical aspects. $\mathrm{Br}$ J Biomed Sci. 2002;59(2):123-7.

2. Trabulsi LR, Keller R, Tardelli Gomes TA. Typical and atypical enteropathogenic Escherichia coli. Emerg Infect Dis. 2002;8(5):508-13.

3. Bonnet R. Growing group of extended-spectrum beta-lactamases: the CTX-M enzymes. Antimicrob Agents Chemother. 2004;48(1):1-14.

4. Jacoby GA. AmpC beta-lactamases. Clin Microbiol Rev. 2009; 22(1):161-82.

5. Djie-Maletz A, Reither K, Danour S, Anyidoho L, Saad E, Danikuu F, et al. High rate of resistance to locally used antibiotics among enteric bacteria from children in Northern Ghana. J Antimicrob Chemother. 2008;61(6):1315-8.

6. Nguyen TV, Le PV, Le CH, Weintraub A. Antibiotic resistance in diarrheagenic Escherichia coli and Shigella strains isolated from children in Hanoi, Vietnam. Antimicrob Agents Chemother. 2005;49(2):816-9.

7. Bartoloni A, Pallecchi L, Benedetti M, Fernandez C, Vallejos Y, Guzman E, et al. Multidrug-resistant commensal Escherichia coli in children, Peru and Bolivia. Emerg Infect Dis. 2006;12(6):907-13.

8. Sepp E, Stsepetova J, Loivukene K, Truusalu K, Koljalg S, Naaber P, et al. The occurrence of antimicrobial resistance and class 1 integrons among commensal Escherichia coli isolates from infants and elderly persons. Ann Clin Microbiol Antimicrob. 2009;8:34.

9. Alikhani MY, Mirsalehian A, Aslani MM. Detection of typical and atypical enteropathogenic Escherichia coli (EPEC) in Iranian children with and without diarrhoea.J Med Microbiol. 2006;55(Pt 9):1159-63.

10. Nakhjavani FA, Emaneini M, Hosseini H, Iman-Eini H, Aligholi $\mathrm{M}$, Jabalameli F, et al. Molecular analysis of typical and atypical enteropathogenic Escherichia coli (EPEC) isolated from children with diarrhoea. J Med Microbiol. 2013;62(Pt 2):191-5.

11. Moyo SJ, Maselle SY, Matee MI, Langeland N, Mylvaganam H. Identification of diarrheagenic Escherichia coli isolated from infants and children in Dar es Salaam, Tanzania. BMC Infect Dis. 2007;7:92.

12. Gunzburg ST, Tornieporth NG, Riley LW. Identification of enteropathogenic Escherichia coli by PCR-based detection of the bundle-forming pilus gene. J Clin Microbiol. 1995;33(5):1375-7.

13. Rey J, Blanco JE, Blanco M, Mora A, Dahbi G, Alonso JM, et al. Serotypes, phage types and virulence genes of shiga-producing Escherichia coli isolated from sheep in Spain. Vet Microbiol. 2003;94(1):47-56.

14. Wikler MA. Performance Standards for Antimicrobial Susceptibility 
Testing: Twentieth Informational Supplement:: Clinical and Laboratory Standards Institute; 2010.

15. Paterson DL, Bonomo RA. Extended-spectrum beta-lactamases: a clinical update. Clin Microbiol Rev. 2005;18(4):657-86

16. Urban C, Mariano N, Bradford PA, Tuckman M, Segal-Maurer S, Wehbeh W, et al. Identification of CTX-M beta-lactamases in Escherichia coli from hospitalized patients and residents of longterm care facilities. Diagn Microbiol Infect Dis. 2010;66(4):402-6.

17. Muzaheed, Doi Y, Adams-Haduch JM, Endimiani A, Sidjabat HE, Gaddad SM, et al. High prevalence of CTX-M-15-producing Klebsiella pneumoniae among inpatients and outpatients with urinary tract infection in Southern India. J Antimicrob Chemother 2008;61(6):1393-4.

18. Naas T, Philippon L, Poirel L, Ronco E, Nordmann P. An SHV-derived extended-spectrum beta-lactamase in Pseudomonas aeruginosa. Antimicrob Agents Chemother.1999;43(5):1281-4.

19. Rayamajhi N, Kang SG, Lee DY, Kang ML, Lee SI, Park KY, et al Characterization of TEM-, SHV- and AmpC-type beta-lactamases from cephalosporin-resistant Enterobacteriaceae isolated from swine. Int J Food Microbiol. 2008;124(2):183-7.

20. Gorge O, Lopez S, Hilaire V, Lisanti O, Ramisse V, Vergnaud G. Selection and validation of a multilocus variable-number tandemrepeat analysis panel for typing Shigella spp. J Clin Microbiol. 2008;46(3):1026-36.

21. Weniger T, Krawczyk J, Supply P, Niemann S, Harmsen D. MIRU-VNTRplus: a web tool for polyphasic genotyping of Mycobacterium tuberculosis complex bacteria. Nucleic Acids Res. 2010;38(suppl2).

22. Tamura K, Peterson D, Peterson N, Stecher G, Nei M, Kumar S. MEGA5: molecular evolutionary genetics analysis using maximum likelihood, evolutionary distance, and maximum parsimony methods. Mol Biol Evol. 2011;28(10):2731-9.

23. Pitout JD, Laupland KB. Extended-spectrum beta-lactamase-producing Enterobacteriaceae: an emerging public-health concern. Lancet Infect Dis. 2008;8(3):159-66.

24. Feizabadi MM, Delfani S, Raji N, Majnooni A, Aligholi M, Shahcheraghi F, et al. Distribution of bla(TEM), bla(SHV), bla(CTX-M) genes among clinical isolates of Klebsiella pneumoniae at Labbafinejad Hospital, Tehran, Iran. Microb Drug Resist. 2010;16(1):49-53.

25. Hamidian M, Tajbakhsh M, Walther-Rasmussen J, Zali MR Emergence of extended-spectrum beta-lactamases in clinica isolates of Salmonella enterica in Tehran, Iran. Jpn J Infect Dis. 2009;62(5):368-71.

26. Tajbakhsh M, Garcia Migura L, Rahbar M, Svendsen CA, Moham madzadeh M, Zali MR, et al. Antimicrobial-resistant Shigella infections from Iran: an overlooked problem? J Antimicrob Chemother. 2012;67(5):1128-33.

27. Ensor VM, Jamal W, Rotimi VO, Evans JT, Hawkey PM. Predominance of CTX-M-15 extended spectrum beta-lactamases in diverse Escherichia coli and Klebsiella pneumoniae from hospital and community patients in Kuwait. Int J Antimicrob Agents. 2009;33(5):487-9.

28. Al-Agamy MH, Shibl AM, Tawfik AF. Prevalence and molecula characterization of extended-spectrum beta-lactamase-producing Klebsiella pneumoniae in Riyadh, Saudi Arabia. Ann Saudi
Med. 2009;29(4):253-7.

29. Yumuk Z, Afacan G, Nicolas-Chanoine MH, Sotto A, Lavigne JP Turkey: a further country concerned by community-acquired Escherichia coli clone O25-ST131 producing CTX-M-15. J Antimicrob Chemother. 2008;62(2):284-8.

30. Albert MJ, Rotimi VO, Dhar R, Silpikurian S, Pacsa AS, Molla AM et al. Diarrhoeagenic Escherichia coli are not a significant cause of diarrhoea in hospitalised children in Kuwait. BMC Microbiol. 2009;9:62.

31. Sonnevend A, Al Dhaheri K, Mag T, Herpay M, Kolodziejek J, Nowotny N, et al. CTX-M-15-producing multidrug-resistant enteroaggregative Escherichia coli in the United Arab Emirates. Clin Microbiol Infect. 2006;12(6):582-5.

32. Vignoli R, Varela G, Mota MI, Cordeiro NF, Power P, Ingold E, et al Enteropathogenic Escherichia coli strains carrying genes encoding the PER-2 and TEM-116 extended-spectrum beta-lactamase isolated from children with diarrhea in Uruguay.J Clin Microbiol. 2005;43(6):2940-3.

33. Amaya E, Reyes D, Vilchez S, Paniagua M, Mollby R, Nord CE, et al. Antibiotic resistance patterns of intestinal Escherichia col isolates from Nicaraguan children. J Med Microbiol. 2011;60(Pt 2):216-22.

34. Bradford PA. Extended-spectrum beta-lactamases in the 21st century: characterization, epidemiology, and detection of this important resistance threat. Clin Microbiol Rev. 2001;14(4):933-51.

35. Ingram PR, Inglis TJ, Vanzetti TR, Henderson BA, Harnett GB, Murray RJ. Comparison of methods for AmpC beta-lactamase detection in Enterobacteriaceae. J Med Microbiol. 2011;60(Pt 6):715-21.

36. Benenson S, Temper V, Cohen MJ, Schwartz C, Hidalgo-Grass C, Block C. Imipenem disc for detection of KPC carbapenemaseproducing Enterobacteriaceae in clinical practice. J Clin Microbiol. 2011;49(4):1617-20.

37. Blanco M, Blanco JE, Dahbi G, Mora A, Alonso MP, Varela G, et al. Typing of intimin (eae) genes from enteropathogenic Escherichia coli (EPEC) isolated from children with diarrhoea in Montevideo, Uruguay: identification of two novel intimin variants (muB and xiR/beta2B). J Med Microbiol. 2006;55(Pt 9):1165-74.

38. Kozub-Witkowski E, Krause G, Frankel G, Kramer D, Appel B, Beutin L. Serotypes and virutypes of enteropathogenic and enterohaemorrhagic Escherichia coli strains from stool samples of children with diarrhoea in Germany. $J$ Appl Microbiol. 2008;104(2):403-10.

39. Campos LC, Franzolin MR, Trabulsi LR. Diarrheagenic Escherichia coli categories among the traditional enteropathogenic E. coli O serogroups--a review. Mem Inst Oswaldo Cruz. 2004;99(6):545-52.

40. Nielsen JB, Albayati A, Jorgensen RL, Hansen KH, Lundgren B Schonning K. An abbreviated MLVA identifies Escherichia coli ST131 as the major extended-spectrum beta-lactamase-producing lineage in the Copenhagen area. Eur J Clin Microbiol Infect Dis. 2013;32(3):431-6.

41. Naseer U, Olsson-Liljequist BE, Woodford N, Dhanji H, Canton $\mathrm{R}$, Sundsfjord A, et al. Multi-locus variable number of tandem repeat analysis for rapid and accurate typing of virulent multidrug resistant Escherichia coli clones. PLoS One. 2012;7(7). 